\title{
Travel Time Map for Identifying The Quality of Airport Access: Case Study Juanda International Airport
}

\author{
Rizky F.A. Istighfaroh, Nursakti A. Pratomoadmojo, Ervina Ahyudanari
}

\begin{abstract}
Air traveler require high reliability time to reach airport, especially for traveler with connecting flight. The airport access may not have an exclusive lane to support the reliability time. Therefore, this research attempted to make a map of the travel time to the airport from districts in airport service area. The map represented the variability of travel time from different period. The data of travel time from 31 districts of Surabaya was collected in different period, morning and afternoon. Weekend and weekday also become the considered variables. Method of recording travel time data was floating car. The speed of the surveyor car was maintained to be the same as other cars. Each segment was analyzed in real travel time. Distances and travel time was the input in producing index map and isochrones. Results from this study showed that the characteristics of travel time was affected by the period to travel. On quality access to airport shows that difference time between the off peaks and peak-hour conditions close to 30 minutes. This proves that the airport access is not an exclusive lane.
\end{abstract}

Index Terms - Airport access, isochrones map, quality of travel, travel time.

\section{INTRODUCTION}

$\mathrm{J}^{\mathrm{s}}$ uanda International Airport is an area that gives attraction on the movement of transportation in Surabaya, so the airport access mode also contributes to the traffic density considering the peak hour, the number of passengers at the Juanda airport reached 2000 more. It means the activities at the airport increase about 2000 private cars on the highway.

The journey to the airport (access) begins when the passenger leaves the house and starts the journey to the airport. The arrival time of passengers at the airport one of them is influenced by the condition of accessibility to the airport. Therefore, in preparing the process of travel, passengers will count down from the departure time of the plane, plus the travel time estimates from the speed of travel accessibility conditions, so obtained a safe span of time where passengers must depart from home to the airport with the time without worry come late.

R.F.A. Istighfaroh is with the Department of Civil Engineering, Institut Teknologi Sepuluh Nopember, Surabaya, Indonesia (e-mail: ervina@ce.its.ac.id)

N.A.Pratomoadmojo is with the Department of Urban and Regional Planning, Institut Teknologi Sepuluh Nopember, Surabaya, Indonesia

E. Ahyudanari is with the Department of Civil Engineering, Institut Teknologi Sepuluh Nopember, Surabaya, Indonesia.
The development of the city served by an airport greatly affects the demand of the airport. Juanda Airport shows the number of passenger growth of $16 \%$ per year where $13 \%$ are passengers from Surabaya. The high rate of growth of passengers increases traffic density on access roads to Juanda. The convenience to Juanda airport has been facilitated by the Waru - Juanda toll road, but access to this toll road still has to use the existing access road which already has high density during rush hour when going to Juanda.

The high density of access roads has resulted in increased travel time to the airport. To know the difference between ideal time and travel time during rush hour on route to airport, conducted study of realibility of travel time to airport juanda. The purpose of this study is to know the significant time between normal conditions and busy conditions.

\subsection{Preview Comparison of Air Travel Time Changes}

Due to the different travel patterns, there are also differences in trends with the arrival time of passengers at the airport. Generally, for passengers at a great distance from the airport or whose travel conditions are unpredictable, more safe time will be taken when departing from home, so the risk of arriving late at the airport can be minimized. Comparison of the change of time of land air travel is shown as in Fig. 1 [1].

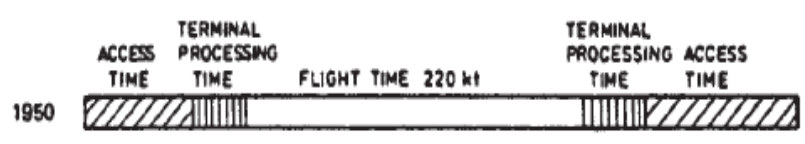

2010

\begin{tabular}{|c|c|c|c|c|}
\hline ACCESS TIME & $\begin{array}{l}\text { TERMINAL } \\
\text { PROCESSING } \\
\text { PIME }\end{array}$ & $\begin{array}{l}\text { FUIGH } \\
\text { TIME } \\
480 \mathrm{kt}\end{array}$ & $\begin{array}{l}\text { TERMINAL } \\
\text { PROCESSING } \\
\text { TIME }\end{array}$ & ACCESS TIME \\
\hline
\end{tabular}

Fig. 1 Comparison of Air Travel Time Changes [1]

Airlines incorporate the realistic travel time access to the airport on their published schedules [2]. The information provided by the airlines helps air travelers to predict their travel time and cost required. This preference influence to the selection of airports to serve their flight [3]. The catchment area of the airport also determines the quality of airport access, especially if the access mix with other routes [4]. Orth et al [5] found that the non-aeronautical travel influence the quality access to the airport. These researches agree that the access 
quality to the airport need an improvement through some techniques. The most important factor that the air travelers will not miss their flight due to the unpredictable travel time.

\section{Methodology}

\subsection{Determination of Zone and Trip generation}

The catchment area of the airport become the variable in this research. This in line with the research conducted by Heng Zou [4]. Determination of the zone of origin of the plane passenger and route selection process is also identified scope of the study and the limitation of the problem. In the determination of zones using district administrative of Surabaya, and center of zone based on upper middle class housing, shopping centers, universities, tourist areas and public transport facilities. The center of zone will be used in analyzing the variation of travel time from each district to the preferred route.

Determination the access route to the airport is limited to reviewing the arterial and collector road class. After mapping the route, running speed survey conducted to obtain the real speed of each access route to Juanda International Airport. The urban roads calculation performed by dividing each segment to get travel time per segment.

\subsection{Measuring travel time by private mode}

Vehicle testing techniques have been used for data collection time travel since the late 1920s. Traditionally, this technique has involved the use of vehicle data collection in which the observer records the cumulative travel time at a predetermined checkpoint along the route of travel. This information is then changed to travel time, speed, and delay for each segment along the survey route. There are several different methods for performing this type of data collection, depending on the survey used in the vehicle and the driving instructions given to the driver.

In this test explains the three levels of instrumentation used to measure travel time by test vehicle:

- Manual record time elapsed at checkpoints that have been set using passengers in test vehicles;

- Distance Measure (DMI) - determines travel times along the corridor based on the speed and distance of information provided by the electronic DMI connected to the test vehicle transmission; and

- Global Positioning System (GPS) - determines vehicle position test and speed by using signals from the Department of Defense (DOD) Earth-orbiting satellite system. This in line with the research conducted by L. Berzina [9]

Travel time data each segment with variation of time. This data is obtained by using survey method of vehicle test technique determined from the distance of travel divided by total travel time which has been reduced by delay. Travel time data each segment is expected to be described speed profile as Fig. 2.

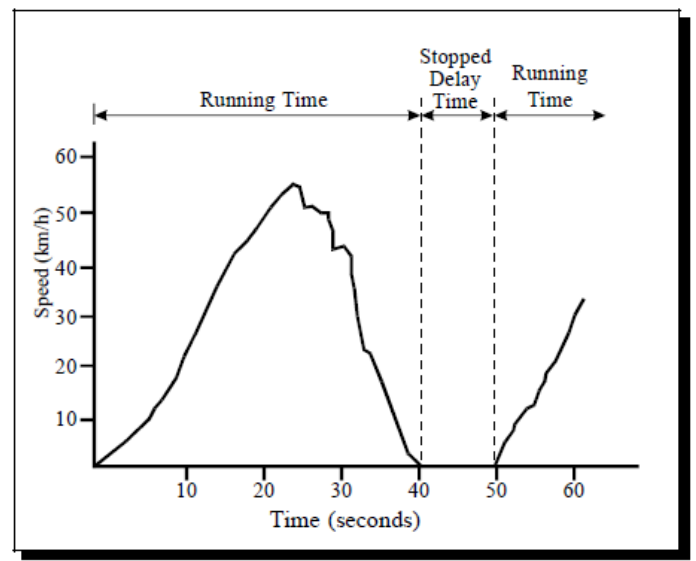

Fig. 2 Speed profile [6]

In this study, the primary data is collected from survey on artery and collector road in Surabaya. Data collection is sample at peak hour. On the route surveyed to calculate the duration of the journey of real conditions in each route, the survey was conducted by private car, 2 people surveyors and for five days Monday, Wednesday, Friday, Saturday and Sunday data sampling peak hour morning and evening except on Sundays once a day because of car free day. with a total of 5 routes in western Surabaya is assumed to enter the toll and 5 main routes to Juanda via primary arterial road and secondary artery the total of sample is 90 .

\section{RESULTS}

\section{A.Variation travel time from each district}

From the data of total real time travel in the morning and afternoon each district listed in Fig. 3, shows that travel time variation in Surabaya District can be seen that the travel time in the afternoon is longer than the morning. This is because in the morning of attraction into Surabaya is bigger than out of Surabaya, while Juanda Airport is administratively located in Sidoarjo, so that in the afternoon attraction access to Juanda Airport is longer than in the morning. The significant difference in time between the afternoon and the morning in almost all districts also shows a significant difference between 30 and 50 minutes. 


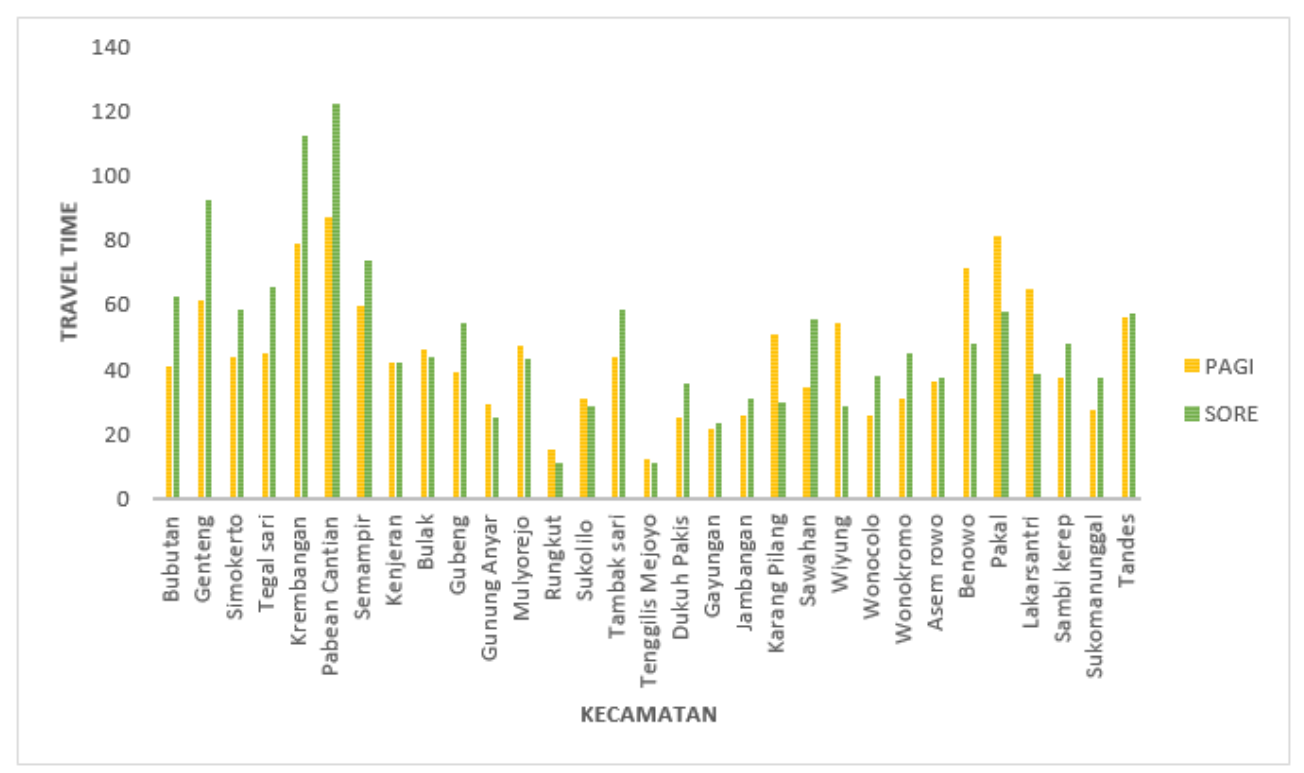

Fig.3 Travel Time Total Each Zone to Juanda Airport Monday

Characteristics of travel time on each route will be viewed in terms of distance and different time plotted comparative survey results between travel time with the length of route options, sampling data total 5 days, interval data collection time in the morning and afternoon. Data retrieval also see peak hour time of Surabaya road segment variation can be seen in the Fig. 4 to Fig. 6 which is the comparison of travel time and distance.

The result of this analysis is found at a distance of $15 \mathrm{Km}$ to $30 \mathrm{Km}$ from the airport there are many variations of travel time this shows in the zone there are many alternative route selection with high traffic density in the zone. Conversely at a distance of $35 \mathrm{~km}$ to $50 \mathrm{~km}$ variations of travel time is shrinking this is due to the location of the airport juanda located south of Surabaya where administratively juanda into the district of Sidoarjo so that the furthest distance from Juanda is asem rowo, benowo, and pakal zone where in this zone most have land use warehousing so there are not many residential areas in the zone so travel time in this zone is lower than than other travel time. In Fig. 4 we have different travel time range although they have same distance, same day but different time

Characteristics of travel time on each route will be viewed in terms of distance and different time plotted comparative survey results between travel time with the length of route options, sampling data total 5 days, interval data collection time in the morning and afternoon. Data retrieval also see peak hour time of Surabaya road segment variation can be seen in the Fig. 4 to Fig. 5 which is the comparison of travel time and distance.

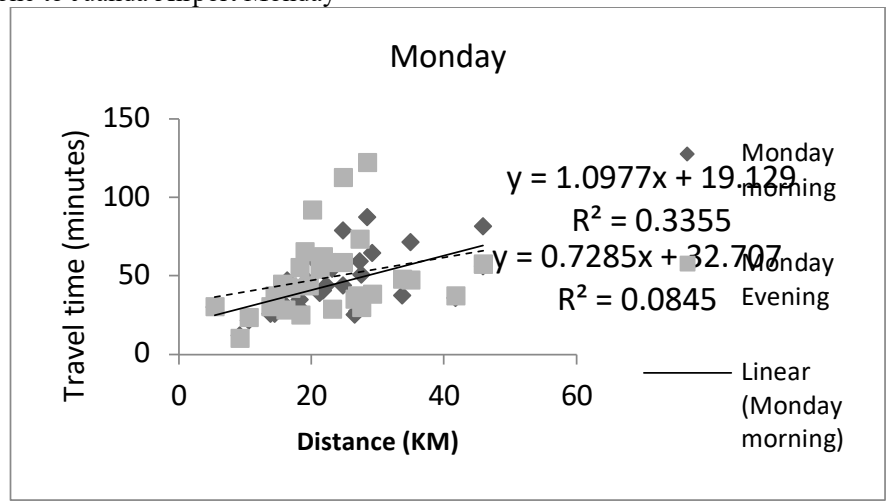

Fig. 4 Travel Time Total Each Zone to Juanda Airport Monday

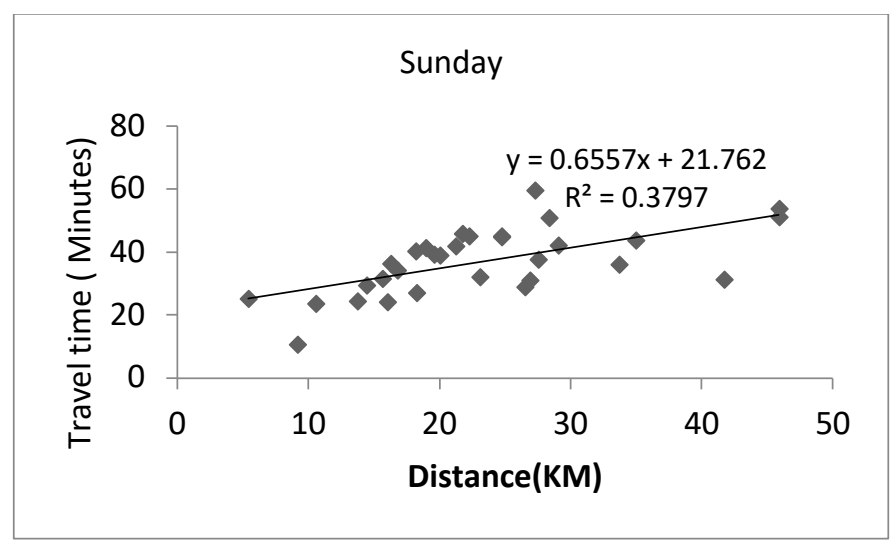

Fig. 5 Travel Time Total Each Zone to Juanda Airport Sunday

The result of this analysis is found at Fih. 4 and Fig.5 distance not significant influence of travel time from each district which is shown by $\mathrm{R}^{2}$ are $0.335,0.3797$, and 0.0845 . It means another variable influance of travel time, it can be caused there are many factors that cause this nonlinearity. including the availability of routes, densit roads, mixing airport access traffic with other traffic, and the location of 
the airport Juanda located south of Surabaya where administratively Juanda into the district of Sidoarjo so that attraction at evening bigger than morning cause people work in Surabaya and live in Sidoarjo.

\subsection{Travel Quality Each route}

Trip quality on each route will be shown on isochrone map and travel time index from terminal 1 of Juanda airport. Quality The first trip is shown with map travel time index This map shows the comparison between real time travel divided by travel time plan where the travel time plan obtained from the comparison of each distance of the road divided by the speed obtained in accordance with the class of road so that the greater the number of comparison between both of which show the higher congestion of a road segment.

Isochrone maps are presented in a variety of days and each day is described as peak hour and minimum conditions. Peak hour condition is a condition where at that hour the condition of the road volume is the most full, and the minimum condition is the condition where the volume of the road is the most open.

Fig. 6 shows the condition of time peak hour travel has 13 different colors where the color will show that the travel time at peak hour to reach the farthest sub-district from Juanda airport takes 130 minutes to reach Benowo and Pakal districts takes 130 minutes. Then in Fig. 9 shows the real travel time on Monday with the minimum conditions of significant color differences there are 10 colors on the real travel time map with the minimum conditions of the furthest sub-district, namely the pakal district is only 100 minutes. In the isochrone map shows different analysis results with the discussion of the characteristics of travel time compared to the previous distance, in the discussion of the characteristics of travel time with distance found the fact that at the farthest distance does not show the longest travel time while on the isochrone map on the contrary, this is due to the analysis of the characteristics of the segment the reference road is the road on the chosen route so that on the route in west Surabaya it is assumed that entering the toll road has a shorter travel time. Whereas the isochrone map in the manufacturing process uses Arcgis auxiliary software where the selection of routes is chosen by Arcgis with many possibilities so that the travel time will be longer.

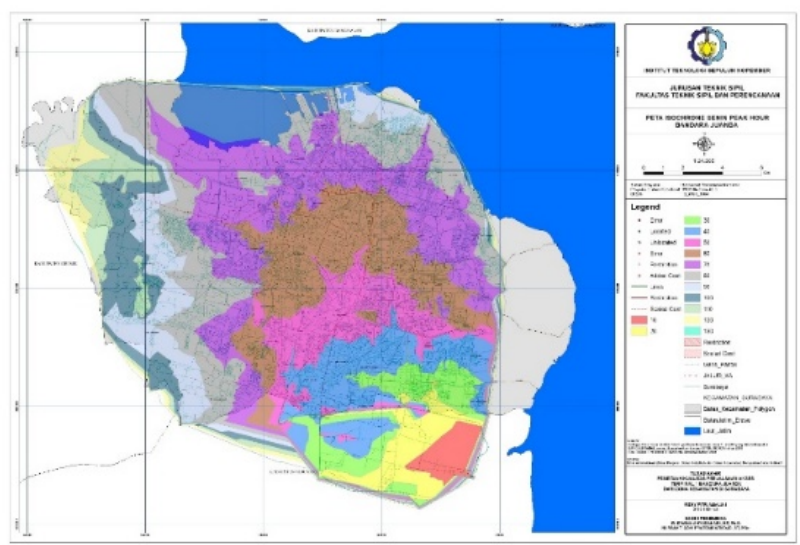

Fig. 6 Isochrone to Juanda Airport

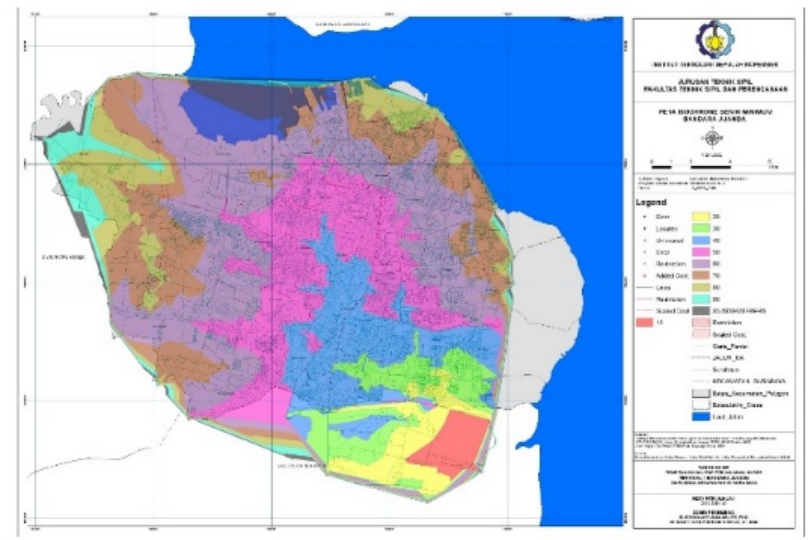

Fig.7 Isochrone to Juanda Airport (Monday Morning Monday Evening)

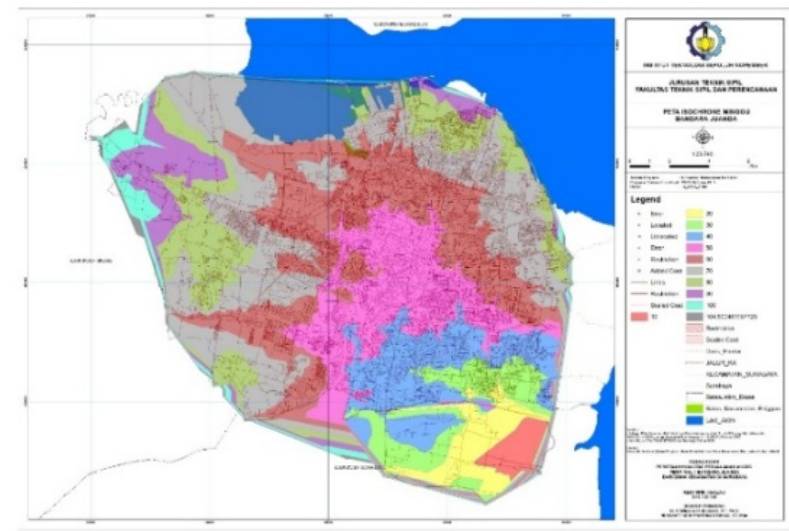

Fig.8 Isochrone to Juanda Airport Sunday

So from the two travel quality parameters ie travel time index map shows on the route option bebarapa road segment has an extreme index, especially on the road Ahmad Yani to Waru to Juanda which is the main road to Juanda Airport and isochrone map shows the significant difference between the minimum condition and peak hour conditions up to 30 minutes this proves that the airport has a great pull on the movement of transportation in Surabaya, so that airport passengers need to pay attention to the process of traveling overland from the air travel process.

\section{CONCLUSIONS}

The characteristics of travel time based on the distance generally shows that the longest distance does not show the longest travel time because the farthest distance in West Surabaya can be overcome through the toll road to Juanda airport so that at a distance of $20 \mathrm{~km}$ to $30 \mathrm{~km}$ is the longest travel time. The quality of travel access to the airport shown on the map of the travel time index map shows the chosen route, some roads have an extreme index, especially on the Ahmad Yani to Waru road to Juanda which is the main road to Juanda Airport and the isochrone map shows significant differences in time between minimum conditions and peak hour conditions up to 30 minutes, this proves that the airport has a big attraction to the movement of transportation in Surabaya, so airport passengers need to consider more the 
process of land travel instead of air travel.

\section{REFERENCES}

[1] N. Ashford, S.A. Mumayiz, and P.H. Wright. Airport Engineering, 544, 2011.

[2] T. Hazledine, R. Bunker, "Airport size and travel time," Journal of Air Transport Management, 32, 17-23, 2013.

[3] J. Wiltshire, "Airport competition: Reality or myth?" Journal of Air Transport Management, 67, 241-248, 2018.

[4] J. X. Heng Zhou, Q. Luo, G. Nikolova, J. Sun, B. Hughes, K. Kelobonye, H. Wang, and T. Falkmer, "Investigating the impact of catchment areas of airports on estimating air travel demand: A case study of regional Western Australia," Journal of Air Transport Management, 70, 91-103, 2018.

[5] H. Orth, O. Frei, U. Weidmann, "Effects of non-aeronautical activities at airports on the public transport access system: A case study of Zurich Airport," Journal of Air Transport Management, 42, 37-46, 2015.

[6] Shawn M. Turner, W. L. Travel time data collection handbook. No. FHWA-PL-98-035. United States. Federal Highway Administration, 1998.

[7] Bruton, M. J. Introduction To Transport Planning. Hutchinson, 1975.

[8] L. Berzina, A. Faghri, M. T. Shourijeh, and M. Li, "Evaluation of travel time data collection techniques: A statistical analysis," Journal of Traffic and Transportation Engineering, 2(6):, 149-158, 2013. 